\title{
Synthesis of High Molecular Weight Nylon 6 by Anionic Polymerization of $\varepsilon$-Caprolactam
}

\author{
Kazue Ueda, Kazunobu Yamada, Makoto NaKai, Tsunetoshi Matsuda, \\ Masahiro HosodA, and Kazuo TAI
}

Research \& Development Center, UNITIKA LTD., 23 Kozakura, Uji, Kyoto 611, Japan

(Received October 20, 1995)

\begin{abstract}
To obtain high molecular weight nylon 6 , the anionic polymerization of $\varepsilon$-caprolactam was investigated in terms of water content in monomer and concentration of catalyst (Grignard reagent; ethyl magnesium bromide) and chain initiator (monofunctional; $N$-acetyl- $\varepsilon$-caprolactam or bifunctional; $N, N^{\prime}$-adipoyl-bis- $\varepsilon$-caprolactam). The weight average molecular weight, $M_{w}=7.0 \times 10^{5}$ (the intrinsic viscosity; $[\eta]=11.2$ ) was obtained using the monofunctional chain initiator, and $M_{w}=9.5 \times 10^{5}([\eta]=14.1)$ was found using the bifunctional chain initiator under the following conditions: water content, $0.013 \mathrm{~mol} \%$; concentration of catalyst, $0.1 \mathrm{~mol} \%$; concentration of chain initiator, $0.03 \mathrm{~mol} \%$ (monofunctional), $0.015 \mathrm{~mol} \%$ (bifunctional); polymerization temperature, $150^{\circ} \mathrm{C}$. In the present study, the molecular weight of the polymer is governed by quantities of active molecular chains. Since water mainly terminates the propagation of molecular chains, minimizing water content in $\varepsilon$-caprolactam is indispensable to maximizing the molecular weight of the polymer.
\end{abstract}

KEY WORDS High Molecular Weight / Nylon 6 / Anionic Polymerization / $\varepsilon$-Caprolactam / Water Content / Catalyst / Grignard Reagent / Chain Initiator

The anionic polymerization of $\varepsilon$-caprolactam has been extensively investigated because of the high yield and high rate of polymerization. ${ }^{1-4}$ Fundamental characters such as various catalysts, ${ }^{2,5,6}$ propagation mechanism $^{7-15}$ and kinetics ${ }^{16-26}$ are well known. Sebenda et al..$^{7,16-22,27}$ studied the propagation mechanism and kinetics of the polymerization, and propose the free ion mechanism and side reaction mechanism. Recently, Stehlicek and Puffr reported that Grignard reagents as anionic catalysts gave much higher rates of the polymerization than sodium- $\varepsilon$-caprolactamate. ${ }^{26}$ On the other hand, Puffr and Vladimirov synthesized the high molecular weight nylon 6 using potassium- $\varepsilon$-caprolactamate as the catalyst at $180^{\circ} \mathrm{C} .{ }^{6}$ The studies directed toward high molecular weight nylon 6 , however, were not performed on the Grignard reagents. In addition, the influence of water content on polymerization was not investigated in spite of the general concept that water content is very important. In this paper, we describe the method for synthesizing high molecular weight nylon 6 by the anionic polymerization of $\varepsilon$-caprolactam. Discussed is the importance of water content and concentration of the catalyst (Grignard reagent) and monoor bifunctional chain initiator.

\section{EXPERIMENTAL}

\section{Materials}

Industrial fiber grade $\varepsilon$-caprolactam as monomer, ethyl magnesium bromide (EtMgBr; Aldrich Chemical Co., Inc.) as catalyst in $3.0 \mathrm{moll}^{-1}$ diethyl ether solution or $1.0 \mathrm{moll}^{-1}$ tetrahydrofuran solution and $N$-acetyl- $\varepsilon$ caprolactam (Ac-CL; Tokyo Chemical Industry Co., Ltd.) as monofunctional chain initiator were used for the polymerization. $N, N^{\prime}$-adipoyl-bis- $\varepsilon$-caprolactam (Ad-CL) as bifunctional chain initiator was prepared from $\varepsilon$-caprolactam and adipoyl-chloride (Aldrich Co., Inc.) in the presence of pyridine, and the product was purified by recrystallization. ${ }^{28} 96 \%$ sulfuric acid (Ishizu
Seiyaku Ltd.) as solvent for viscosity measurement and hexafluoro-2-propanol (HFIP; Ishizu Seiyaku Ltd.) as the mobile phase in gel permeation chromatography were of reagent grade and used without further purification.

\section{Polymerization}

Water in $\varepsilon$-caprolactam was removed to less than $0.013 \mathrm{~mol} \%$ by bubbling dry argon gas for $5 \mathrm{~h}$ in a three-neck flask at $120^{\circ} \mathrm{C}$. Water content was controlled by adding water to this $\varepsilon$-caprolactam and measured by Karl Fischer auto titration equipment (Hiranuma Industrial Co., AQV-5S ). The chain initiator was injected into $\varepsilon$-caprolactam with controlled water content. The mixture of monomer and initiator was poured into a glass tube (inside diameter $20 \mathrm{~mm}$, volume $20 \mathrm{ml}$ ) beforehand dried by heating above $100^{\circ} \mathrm{C}$ under $10 \mathrm{~Pa}$ of vacuum. The catalyst (EtMgBr) solution was injected into the tube via a syringe, and the tube was sealed after unnecessary solvent was evaporated at $10 \mathrm{~Pa}$. Polymerization was carried out with shaking in an oil bath at $130-190^{\circ} \mathrm{C}$ (thermostated at $\left.\pm 1.0^{\circ} \mathrm{C}\right)$.

As the polymerization of $\varepsilon$-caprolactam proceeded, the viscosity of the system increased, and fluidity disappeared. We called this point the solidification point, when the fluidity of the system disappeared, with glass tube in tilted position. We define the time from the beginning of the polymerization to the solidification point as the solidification time. Since it was confirmed that conversion almost reached $20 \%$ at the solidification time, this time was conveniently used for estimation of reaction rate. The polymerization was stopped at 2.5 times (using $0.5 \mathrm{~mol} \% \mathrm{EtMgBr}$ ) or 6 times (using $0.1 \mathrm{~mol} \% \mathrm{EtMgBr}$ ) of the solidification time. It was confirmed that at that time conversion was about $100 \%$. Termination of the polymerization was carried out by quenching to dry ice/methanol temperature $\left(-78^{\circ} \mathrm{C}\right)$. The product was shaved with a boring machine and analyzed. Monomer and oligomer in the polymer were extracted by 


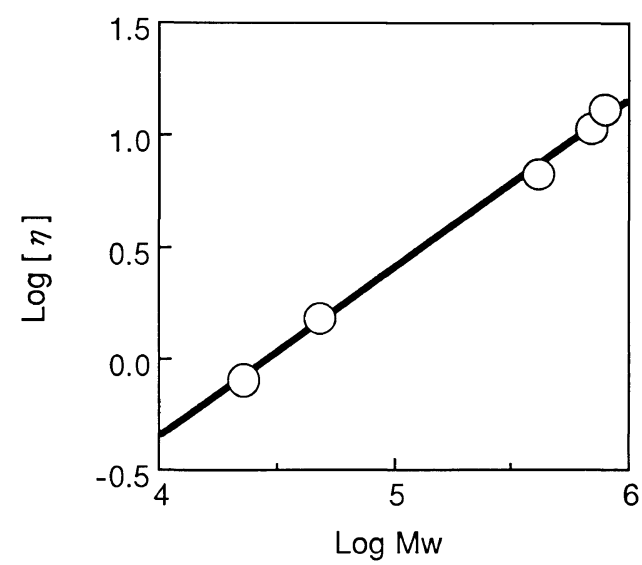

Figure 1. Relation between $\log [\eta]$ and $\log M_{w}$. [ $\left.\eta\right]$ was determined with polymer concentration below $0.2 \mathrm{~g} \mathrm{dl}^{-1}$ (5 points) using $\mathrm{H}_{2} \mathrm{SO}_{4}$ at $25^{\circ} \mathrm{C} . M_{w}$ was measured by LS using HFIP at $30^{\circ} \mathrm{C}$.

boiling water in a flask for $5 \mathrm{~h}$. The monomer content in the extract was measured by liquid chromatography (Column; Waters C18 Purecil, mobile phase; $0.1 \mathrm{M}$ $\mathrm{NaH}_{2} \mathrm{PO}_{4}+\mathrm{H}_{3} \mathrm{PO}_{4}, \mathrm{pH} 3.0$ ), and conversion was calculated from change in monomer content before and after polymerization.

\section{Molecular Weight Determination}

The molecular weight of the polymers was conventionally evaluated by intrinsic viscosity measurement ([ $\eta]$; $96 \%$ sulfuric acid, at $25^{\circ} \mathrm{C}$ ). The concentration for this measurement was below $0.2 \mathrm{~g} \mathrm{dL}^{-1}$ because of nonNewtonian behavior in the ordinary concentration of the measurement (less than $0.5 \mathrm{~g} \mathrm{dL}^{-1}$ ). ${ }^{29}$ Light scattering (LS; Wyatt LTD., DAWN-F) measurements for the polymer with various $[\eta]$ were carried out in HFIP to obtain weight average molecular weight $\left(M_{w}\right)$.

Figure 1 shows the relation between $[\eta]$ and $M_{w}$ of the polymer in this study. Linear regression analysis was applied to the data and coefficients of MarkHouwink-Sakurada equation were determined as follows:

$$
M_{w}=2.81 \times 10^{4} \times[\eta]^{1.35}
$$

$M_{w}$ of the polymers under various polymerization conditions were calculated by eq 1 using observed $[\eta]$.

Gel permeation chromatography (GPC; TSK gel $\mathrm{GMH}-\mathrm{H}+\mathrm{G} 7000 \mathrm{H}$ ) measurements were carried out with HFIP as the mobile phase. In general, GPC measurements give $M_{w}$, the number average molecular weight $\left(M_{n}\right)$ and polydispersity $\left(P=M_{w} / M_{n}\right)$. Calibration of the column could not be carried out, since we had no sample of standard nylon 6 with monodispersed molecular weight. Therefore, only $P$ reliably obtained from GPC measurement was used. Details of the analysis will be published elsewhere. ${ }^{30}$

\section{RESULTS AND DISCUSSION}

\section{Influence of Water Content}

The influence of water content on anionic polymerization is demonstrated in Figures 2 and 3. Here in Figure 2 the experimental results of the solidification time of the polymerization are shown as a function of the concentration of the chain initiator (Ac-CL) at various

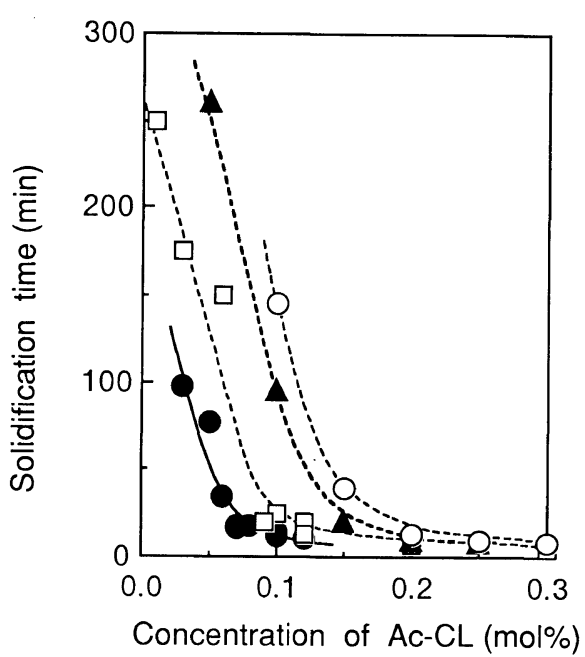

Figure 2. Effects of water content on the solidification time, where the solidification time is plotted against the concentration of the chain initiator (Ac-CL). Polymerization conditions: temperature, $150^{\circ} \mathrm{C}$; concentration of catalyst $(\mathrm{EtMgBr}), 0.5 \mathrm{~mol} \%$; water content, $0.013 \mathrm{~mol} \%$ (○), $0.038 \mathrm{~mol} \%(\square), 0.063 \mathrm{~mol} \%$ (A), $0.088 \mathrm{~mol} \%(\bigcirc)$, respectively.

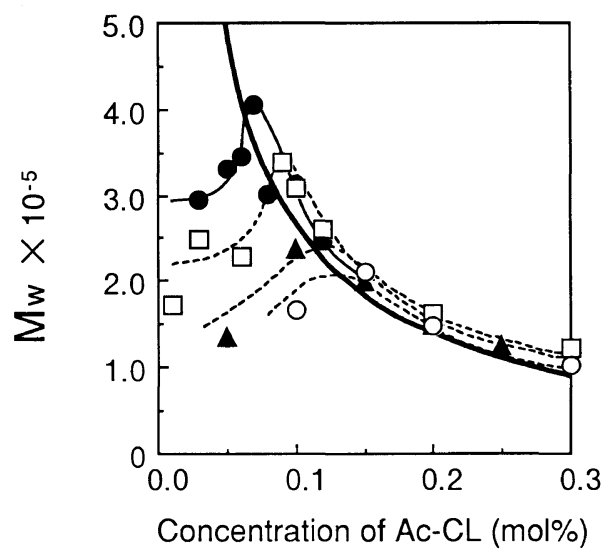

Figure 3. Effects of water content on $M_{w}$, where $M_{w}$ is plotted against the concentration of the chain initiator (Ac-CL). Polymerization conditions: temperature, $150^{\circ} \mathrm{C}$; concentration of catalyst $(\mathrm{EtMgBr})$, $0.5 \mathrm{~mol} \%$; water content, $0.013 \mathrm{~mol} \% \quad(\bigcirc), 0.038 \mathrm{~mol} \% \quad(\square)$, $0.063 \mathrm{~mol} \%$ ( $\Delta), 0.088 \mathrm{~mol} \%(\bigcirc)$, respectively. The thick solid line (-) is the calculated $M_{w}$.

water contents; $0.013,0.038,0.063$, and $0.088 \mathrm{~mol} \%$, respectively. The concentration of catalyst (EtMgBr) was kept constant at $0.5 \mathrm{~mol} \%$. As the Ac-CL concentration decreases, the solidification time gradually increases at every water content. Solidification time becomes longer with increasing water content. At low concentration of the chain initiator, the solidification time becomes steeply longer at every water content. Figure 3 shows $M_{w}$ of the polymer as a function of Ac-CL concentration under the same conditions as Figure 2. The relation between $M_{w}$ and Ac-CL concentration is shown by a curved plot with a maximum peak. As water content decreases, the maximum $M_{w}$ increases. $M_{w}\left(4.0 \times 10^{5}\right)$ was maximum at $0.07 \mathrm{~mol} \%$ of Ac-CL and $0.013 \mathrm{~mol} \%$ water content.

The thick solid line in Figure 3 indicates the calculated $M_{w}$ assuming eq 2 .

$$
M_{w}=\frac{P \cdot M_{\mathrm{CL}}}{[\mathrm{I}] /[\mathrm{M}]}
$$

Here, [I] is the concentration of the chain initiator 
Table I. Reaction mechanisms of the anionic polymerization of $\varepsilon$-caprolactam - $^{3,27,31}$

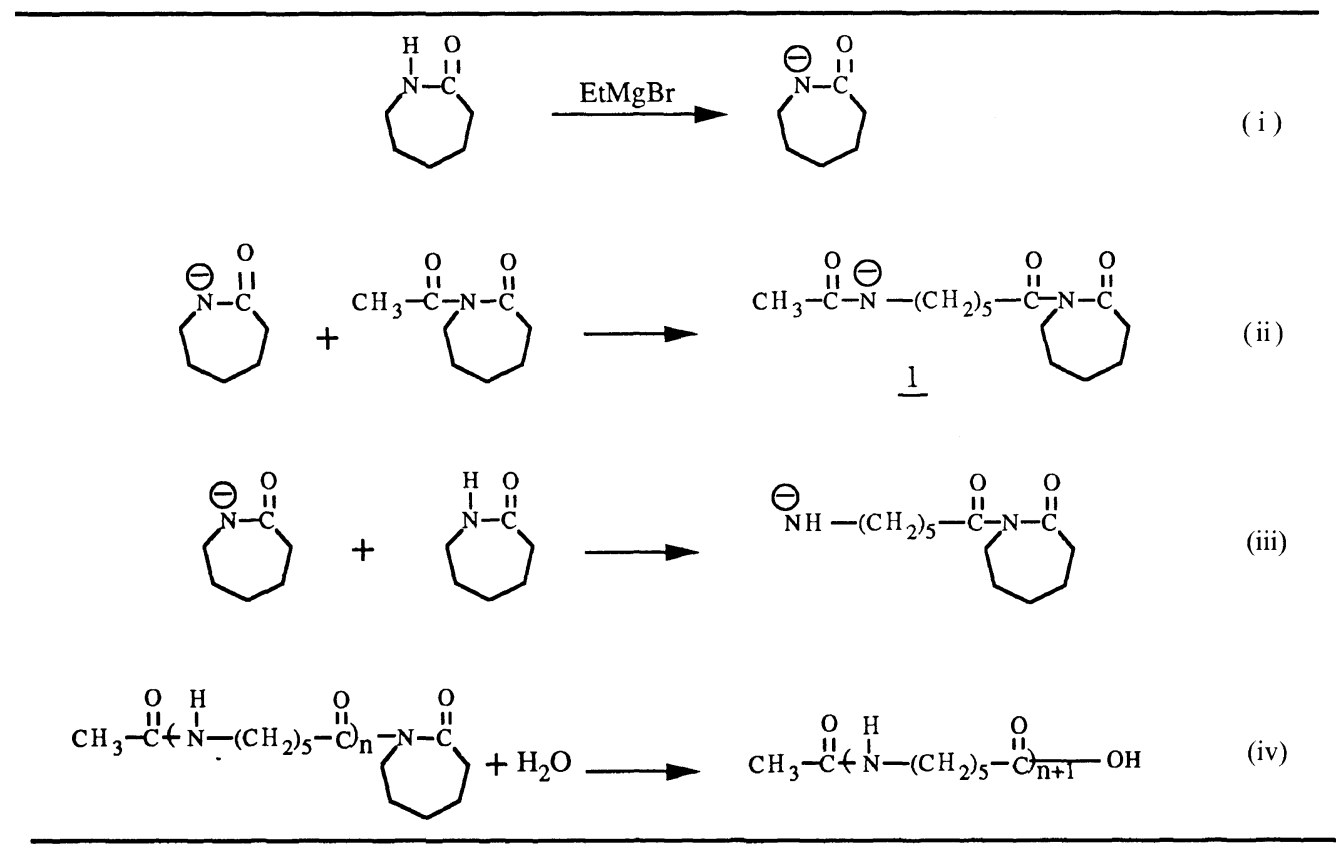

$\left(\mathrm{molg}^{-1}\right)$, and $[\mathrm{M}]$ is the initial concentration of the monomer $\left(\mathrm{mol} \mathrm{g}^{-1}\right)$, and $M_{\mathrm{CL}}$ is the molecular weight of $\varepsilon$-caprolactam. $P$ means polydispersity $\left(P=M_{w} / M_{n}\right)$, the value of which was estimated to be 2.3 by GPC measurements. As for this polymerization, it was proposed that the initiation reaction proceeds according to the eq $\mathrm{i}$ and $\mathrm{ii}$ in Table I (the main reactions), ${ }^{3,27,31}$ and the molecular chains extend with $\mathbf{1}$ as an initiator. Therefore, if the polymerization proceeds ideally, the number of chains corresponds to the number of initiators, represented by eq 2 . The smaller amount of initiator might provide the higher molecular weight.

In Figure 3, the right side of the peak top in each curve closely follows the calculated line. The maximum value of $M_{w}$ obtained by these experiments (water content $0.013 \mathrm{~mol} \%$ ) is $4.0 \times 10^{5}$, which corresponds to $M_{w}=$ $3.7 \times 10^{5}$ calculated from the concentration of Ac-CL $(0.07 \mathrm{~mol} \%)$. Therefore, it is clarified that the high molecular weight nylon 6 is obtained along with the line by controlling the water content and the concentration of chain initiator Ac-CL.

In Figure 3, the left side of the peak top in each curve deviates appreciably from the calculated line. The solidification time at low Ac-CL concentration (especially below $0.05 \mathrm{~mol} \%$ ) becomes longer such as in Figure 2 even at the water content $0.013 \mathrm{~mol} \%$. The conversion reaches only $70-85 \%$ in the left side of the peak top. The long solidification time is the result of low concentration of the growing chain end. Consequently, the side reaction like eq iii in Table I with slow reaction rate $^{3}$ becomes significant, which is generally ignored in polymerization using a high concentration of the chain initiator. The influence of water is not ignored for the anionic polymerization even at $0.013 \mathrm{~mol} \%$, which is comparable with the concentration of Ac-CL $(0.03-$ $0.07 \mathrm{~mol} \%$ ). Water causes the side reactions like eq iv in Table I and stops the propagation of the molecular chain. The deviation between the experimental $M_{w}$ and the calculated $M_{w}$ is caused by all factors described above.

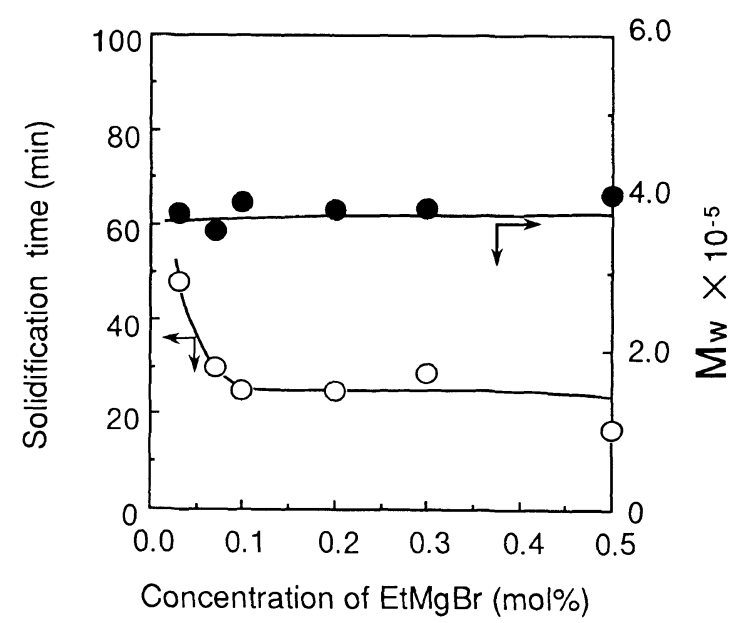

Figure 4. Effects of concerntration of catalyst $(\mathrm{EtMgBr})$ on the solidification time and $M_{w}$. Polymerization was carried out at: temperature, $150^{\circ} \mathrm{C}$; concentration of chain initiator (Ac-CL), $0.07 \mathrm{~mol} \%$; water content, $0.013 \mathrm{~mol} \%$.

On the anionic polymerization with Grignard reagents, it was revealed the water content and the chain initiator concentration controls the molecular weight of the product.

\section{Effects of Concentration of Catalyst}

To clarify the effects of the catalyst, the solidification time and $M_{w}$ of the product versus the concentration of catalyst $\mathrm{EtMgBr}$ were investigated in the presence of $0.013 \mathrm{~mol} \%$ water, which is shown in Figure 4. The initiator Ac-CL concentration was kept constant at $0.07 \mathrm{~mol} \%$. Although the solidification time becomes longer below $0.1 \mathrm{~mol} \%$ of EtMgBr, $M_{w}$ of the polymer is constant at about $3.9 \times 10^{5}([\eta]=6.6)$. It is suggested that the molecular weight of the product does not mainly depend on the concentration of the catalyst. To achieve the high molecular weight, however, the polymerization should be ideally initiated by the minimum concentration of 1 formed with molar equivalent of the catalyst EtMgBr 


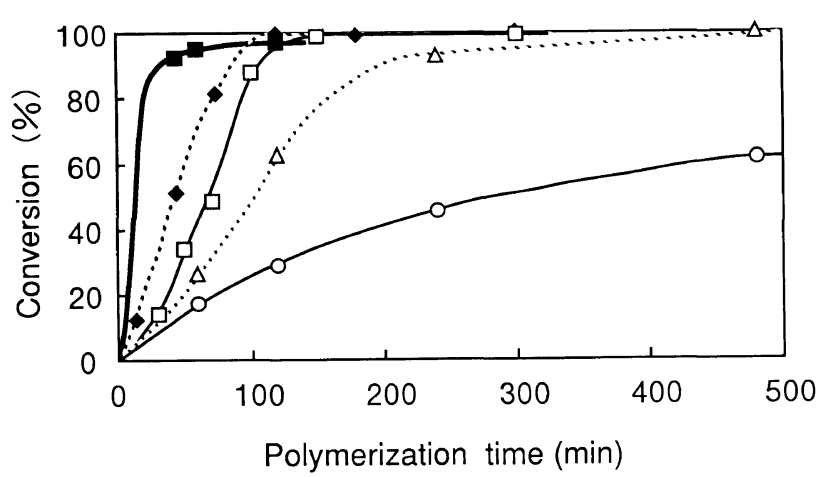

Figure 5. Time-conversion curves at various polymerization temperature. Polymerization conditions: temperature, $130^{\circ} \mathrm{C}(\mathrm{O}), 140^{\circ} \mathrm{C}$ $(\triangle), 150^{\circ} \mathrm{C}(\square), 170^{\circ} \mathrm{C}(\diamond), 190^{\circ} \mathrm{C}(\square)$, respectively; concentration of catalyst (EtMgBr), $0.1 \mathrm{~mol} \%$; chain initator (Ac-CL), $0.05 \mathrm{~mol} \%$; water content, $0.013 \mathrm{~mol} \%$.

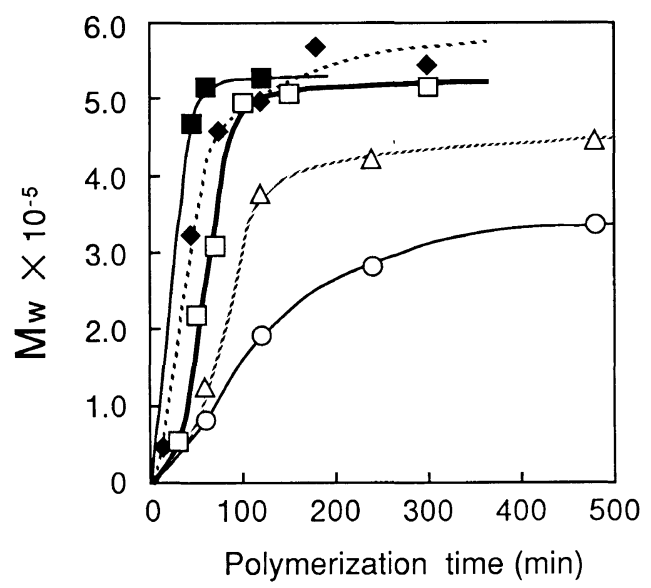

Figure 6. Effects of the polymerization temperature on $M_{w}$, where $M_{w}$ is plotted against the polymerization time at various temperatures. Polymerization conditions: temperature, $130^{\circ} \mathrm{C}(\bigcirc), 140^{\circ} \mathrm{C}(\triangle), 150^{\circ} \mathrm{C}$ $(\square), 170^{\circ} \mathrm{C}(\bullet), 190^{\circ} \mathrm{C}(\square)$, respectively; concentration of catalyst (EtMgBr), $0.1 \mathrm{~mol} \%$; chain initiator (Ac-CL), $0.05 \mathrm{~mol} \%$; water content, $0.013 \mathrm{~mol} \%$.

and the chain initiator Ac-CL. Consequently, the concentration of EtMgBr is required to approximate the concentration of Ac-CL closely and not to increase the side reaction or not to decrease the polymerization rate. We conclude the concentration of the catalyst should be reduced to $0.1 \mathrm{~mol} \%$. The polymerization was carried out at $0.1 \mathrm{~mol} \%$ of $\mathrm{EtMgBr}$.

\section{Effects of Temperature}

The catalytic system consisting of the catalyst (EtMgBr) and the chain initiator (Ac-CL or Ad-CL) may provide advantageous polymerization at lower temperature. Polymerization temperature is an important factor for controlling the reaction rate of the main reaction and side reaction. The effects of temperature on the polymerization were studied and the results are shown in Figures 5 and 6 . Here, the concentration of catalyst (EtMgBr) is $0.1 \mathrm{~mol} \%$, the concentration of chain initiator (Ac-CL) is $0.05 \mathrm{~mol} \%$ and water content is $0.013 \mathrm{~mol} \%$. Figure 5 shows the relation between the conversion and the polymerization time at $130-190^{\circ} \mathrm{C}$ using Ac-CL. The conversion increases monotonously with polymerization time for all temperatures. The time to reach $100 \%$ conversion becomes short with increase

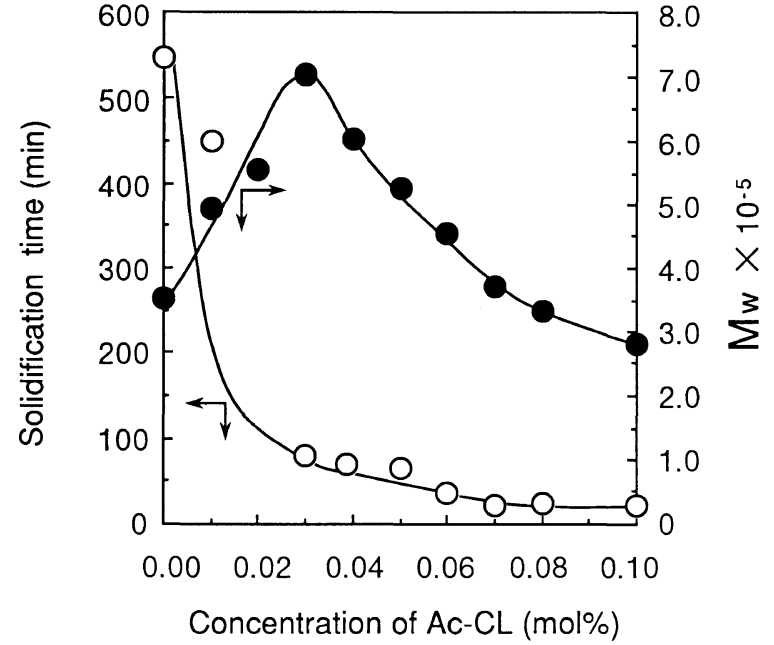

Figure 7. Plots of solidification time and $M_{w}$ against the concentration of the monofunctional chain initiator (Ac-CL). Polymerization conditions: temperature, $150^{\circ} \mathrm{C}$; concentration of catalyst $(\mathrm{EtMgBr})$, $0.1 \mathrm{~mol} \%$; water content, $0.013 \mathrm{~mol} \%$.

in temperature. This means that the polymerization rate increases with temperature. The conversion at $190^{\circ} \mathrm{C}$ does not reach 100\% (about 97\%), since an equiliblium monomer exists probably. ${ }^{32}$

Figure 6 shows $M_{w}$ of the polymer versus the polymerization time at $130-190^{\circ} \mathrm{C}$ using Ac-CL. The time to reach the steady state of $M_{w}$ decreases with increase in temperature. $M_{w}$ of the polymer synthesized at $150-190^{\circ} \mathrm{C}$ was about $5.0 \times 10^{5}$ and at 130 and $140^{\circ} \mathrm{C}$, only $3.3 \times 10^{5}$ and $4.4 \times 10^{5}$ respectively.

In spite of decrease in side reactions at lower temperature $\left(130\right.$ and $\left.140^{\circ} \mathrm{C}\right)$, it takes a very long time to reach $100 \%$ conversion, since the main reaction becomes slower than that at higher temperature. $M_{w}$ of the polymers synthesized at $170^{\circ} \mathrm{C}$ and $190^{\circ} \mathrm{C}$ are same as at $150^{\circ} \mathrm{C}$ despite the increase in polymerization rate. The increase of $M_{w}$ after reaching $100 \%$ conversion at $170^{\circ} \mathrm{C}$ is almost within experimental error. It is considered that the lower temperature is favorable to decrease side reactions, so that $150^{\circ} \mathrm{C}$ is the most suitable temperature of the polymerization.

\section{Maximum $M_{w}$ by Monofunctional Initiator}

To obtain higher molecular weight nylon 6 , polymerization was carried out at $0.1 \mathrm{~mol} \%$ of EtMgBr and $0.013 \mathrm{~mol} \%$ of water content. The solidification time and $M_{w}$ of the polymer as a function of the concentration of the chain initiator (Ac-CL) are shown in Figure 7. As the concentration of the chain initiator decreases, $M_{w}$ of the polymer increases gradually above $0.03 \mathrm{~mol} \%$ of Ac-CL. $M_{w}$ maximum is $7.0 \times 10^{5}([\eta]=11.2)$, at $0.03 \mathrm{~mol} \%$ of Ac-CL concentration. Below $0.03 \mathrm{~mol} \%$ of Ac-CL, $M_{w}$ of the polymer decreases. This is similar to the results in Figure 3 . The solidification time increases monotonously and steep increase are observed below the chain initiator $0.03 \mathrm{~mol} \%$. This behavior is similar to that in Figure 2. Consequently, by controlling the catalyst concentration, the increase of $M_{w}$ was more in the region of the lower concentration of the chain initiator than that of Figure $3(0.07 \mathrm{~mol} \%$ of Ac-CL).

The observed maximum value of $M_{w}\left(7.0 \times 10^{5}\right)$ is somewhat lower than the calculated value of $M_{w}$ 


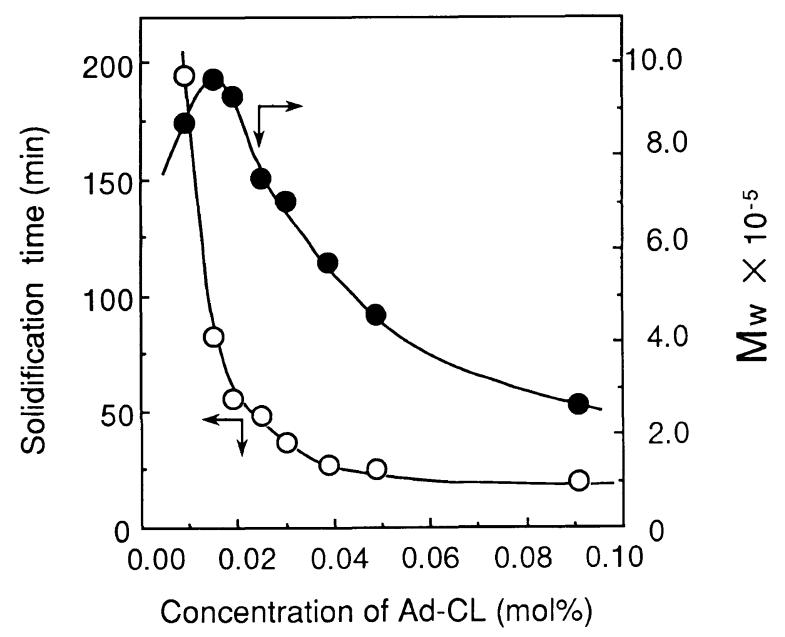

Figure 8. Plots of solidification time and $M_{w}$ against the concentration of the bifunctional chain initiator (Ad-CL). Polymerization conditions: temperature, $150^{\circ} \mathrm{C}$; concentration of catalyst (EtMgBr), $0.1 \mathrm{~mol} \%$; water content, $0.013 \mathrm{~mol} \%$.

$\left(8.6 \times 10^{5}\right)$ assuming that the concentration of Ac-CL is $0.03 \mathrm{~mol} \%$. The reason is attributed to the increase of side reactions like eq iii in Table I. Higher $M_{w}$ than $7.0 \times 10^{5}$ using the monofunctional chain initiator (AcCL) could not be achieved, since water in $\varepsilon$-caprolactam (even $0.013 \mathrm{~mol} \%$ ) and in EtMgBr solution may not be ignored in these low concentration of the catalyst and the chain initiator. It is experimentally difficult to reduce the water content below $0.013 \mathrm{~mol} \%$. Therefore, it is recognized that the highest molecular weight of the polymer using the monofunctional chain initiator (AcCL) is $M_{w}=7.0 \times 10^{5}$.

\section{Maximum $M_{w}$ by Bifunctional Initiator}

Polymerization using the bifunctional chain initiator (Ad-CL) was carried out to achieve further high molecular weight. Figure 8 shows the solidification time and $M_{w}$ of the polymer as a function of the concentration of the chain initiator Ad-CL at $0.1 \mathrm{~mol} \%$ of EtMgBr . As the concentration of the chain initiator decreases, $M_{w}$ of the polymer increases gradually above $0.015 \mathrm{~mol} \%$ of Ad-CL. $M_{w}$ maximum is $9.5 \times 10^{5}([\eta]=14.1)$, which is achieved at $0.015 \mathrm{~mol} \%$ of Ad-CL concentration. $M_{w}$ of the polymer decreases below $0.015 \mathrm{~mol} \%$ of Ad-CL. This is similar to the results in Figure 7. The solidification time is also similar to that in Figure 7 except that the time is about half.

The concentration of the bifunctional chain initiator (Ad-CL) providing maximum $M_{w}$ is $0.015 \mathrm{~mol} \%$, which is half the monofunctional chain initiator (Ac-CL, $0.03 \mathrm{~mol} \%$ ), since Ad-CL has 2 active molecular chain ends per molecule. Maximum $M_{w}=9.5 \times 10^{5}$ (Ad-CL, $0.015 \mathrm{~mol} \%$ ) obtained from the bifunctional chain initiator is lower than the calculated $M_{w}\left(1.7 \times 10^{6}\right)$. This considerable deviation between the observed and calculated $M_{w}$ may be due to the relative increase of side reactions such as eq iii in Table $I$. The highest molecular weight of the polymer obtained by the bifunctional chain initiator is $M_{w}=9.5 \times 10^{5}$.

\section{CONCLUSION}

To obtain high molecular weight nylon 6 , the anionic polymerization of $\varepsilon$-caprolactam was explored. Maximum molecular weights of $M_{w}=7.0 \times 10^{5} \quad([\eta]=11.2)$ using the monofunctional chain initiator (Ac-CL) and $M_{w}=9.5 \times 10^{5}([\eta]=14.1)$ using the bifunctional one (Ad-CL) were achieved. It was clarified that the molecular weight of the polymer depends on quantities of active molecular chains, and minimizing water content is necessary for maximal molecular weight, since water mainly terminates the propagation of the molecular chains. The essential conditions for maximum $M_{w}$ are; (1) water content in $\varepsilon$-caprolactam should be below $0.013 \mathrm{~mol} \%$, (2) relation between the concentration of the catalyst and the chain initiator is important, and $0.1 \mathrm{~mol} \%$ of the catalyst $(\mathrm{EtMgBr})$ and $0.03 \mathrm{~mol} \%$ (monofunctional) or $0.015 \mathrm{~mol} \%$ (bifunctional) of the chain initiator are required, (3) $150^{\circ} \mathrm{C}$ is the most suitable polymerization temperature without decrease of the polymerization rate and without increase of side reactions.

\section{REFERENCES}

1. J. Sebenda, "Comprehensive Chemical Kinetics," Vol. 15, C. H. Bamfordand and C. F. H. Tipper, Ed., Elsevier, Amsterdam, 1976, p 279.

2. H. Sekiguchi, "Ring-Opening Polymerization," Vol. 2, K. J. Ivin and T. Saegusa, Ed., Elsevier, London, 1984, p 832.

3. J. Sebenda, "Comprehensive Polymer Science," Vol. 3, C. F. H. Tipper and C. H. Bamford, Ed., Pergamon Press, Oxford, 1988.

4. R. Puffr, "Lactam-Based Polyamides," Vol. 1, R. Puffr and V. Kubánek, Ed., CRC Press, Boca Raton, 1991.

5. J. Karger-Kocsis and L. Kiss, J. Polym. Sci., Polym. Symp., 69, 67 (1981).

6. R. Puffr and N. Vladimirov, Makromol. Chem., 194, 1765 (1993).

7. J. Sebenda, J. Macromol. Sci. Chem., A6, 1145 (1972).

8. G. Champetier and H. Sekiguchi, J. Polym. Sci., 48, 309 (1960).

9. H. Sekiguchi and B. Coutin, J. Polym. Sci., Chem. Ed., 11, 1601(1973).

10. T. M. Frunze, V. A. Kotel'nikov, T. V. Volkova, V. V. Kurashev, S. P. Davtyan, and V. V. Korshak, Dokl. Akad. Nauk SSSR, 255, 612 (1980).

11. T. M. Frunze, V. A. Kotel'nikov, T. V. Volkova, V. V. Kurashev, S. P. Davtyan, and I. V. Stankevich, Acta Polym., 32, 31 (1981)

12. T. M. Frunze, V. A. Kotel'nikov, T. V. Volkova, and V. V. Kurashev, Eur. Polym. J., 17, 1079 (1981)

13. N. Mougin, C. A. Veith, R. E. Cohen, and Y. Gnanou, Macromolecules, 25, 2004 (1992).

14. H. Tani and T. Konomi, J. Polym. Sci. A-1, 6, 2295 (1968).

15. R. Z. Greenley, J. C. Stauffer, and J. E. Kurz, Macromolecules, 2, 561 (1969).

16. E. Sittler and J. Sebenda, Collect. Czech. Chem. Commun., 33, 270 (1968).

17. E. Sittler and J. Sebenda, Collect. Czech. Chem. Commun., 33, 3182 (1968)

18. J. Sebenda, J. Polym. Sci. C, 23, 169 (1968).

19. J. Sebenda and V. Kouril, Eur. Polym. J., 8, 437 (1972).

20. J. Sebenda, A. Stiborová, L. Lochman, and Z. Bukac, Org. Prepr. Proced. Int., 12, 289 (1980) [Chem. Abstr., 94, 16165 (1981)].

21. J. Stehlicek and J. Sebenda, Eur. Polym. J., 22, 769 (1986).

22. J. Stehlicek, J. Labsky, and J. Sebenda, Collect. Czech. Chem. Commun., 32, 545 (1987).

23. T. M. Frunze, S. P. Davtyan, V. A. Kotel'nikov, T. V. Volkova, and V. V. Kurashev, Vysokomol. Soedin., Ser. B, 23, 388 (1981). 
24. V. G. Frolov, Vysokomol. Soedin., Ser. B, 25, 134 (1983).

25. S. Barzakay, M. Levy, and D. Vofsi, J. Polym. Sci. A-1, 5, 965 (1967).

26. J. Stehlicek and R. Puffr, Macromol. Chem., 193, 10, 2539 (1992).

27. J. Sebenda, Preprints of Scientific Papers I, IUPAC International Symposium on Macromolecular Chemistry, Tokyo-Kyoto, 1966, p 251.

28. S. Chrzczonowlcz, J. Kowalski, and M. Wlodarczyk, Bull. Acad.
Polon. Sci., Sér. Sci. Chim., 14, 751 (1966).

29. M. Turuta, "Polyamide-jusi,"' Nikkan-kõgyõ-shinbun, Tokyo, 1961.

30. K. Ueda, K. Hattori, M. Nakai, and K. Tai, to be published.

31. S. Barzakay, M. Levy, and D. Vofsi, J. Polym. Sci. B, 3, 601 (1965).

32. H. Yumoto, J. Chem. Phys., 29, 1234 (1958). 